
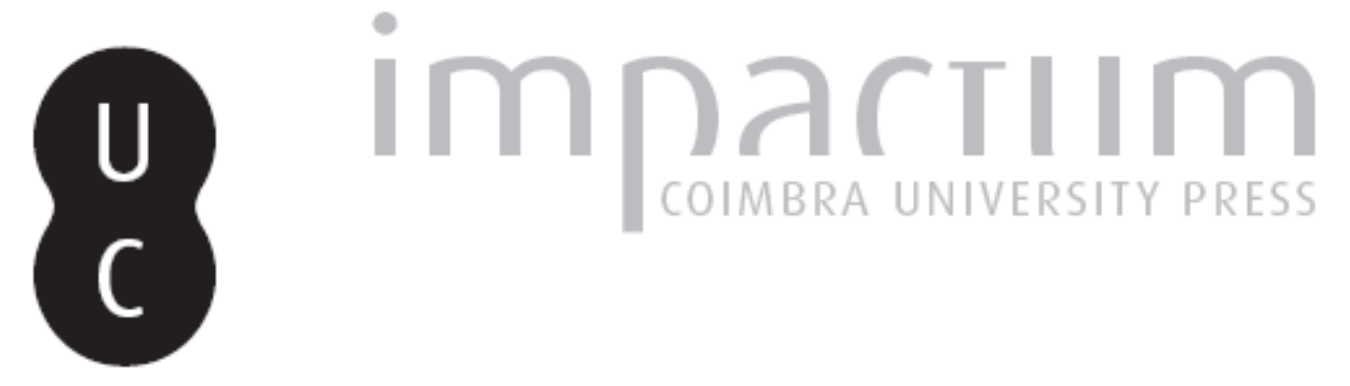

\title{
A mestria do poeta lírico: notas sobre Horácio (7): Ode 2.3
}

\section{Autor(es): $\quad$ André, Carlos Ascenso}
Publicado por: Associação Portuguesa de Estudos Clássicos; Instituto de Estudos Clássicos

URL persistente:

URI:http://hdl.handle.net/10316.2/30430

DOI:

DOI:http://dx.doi.org/10.14195/0872-2110_51_6

Accessed : $\quad$ 26-Apr-2023 15:35:16

A navegação consulta e descarregamento dos títulos inseridos nas Bibliotecas Digitais UC Digitalis, UC Pombalina e UC Impactum, pressupõem a aceitação plena e sem reservas dos Termos e Condições de Uso destas Bibliotecas Digitais, disponíveis em https://digitalis.uc.pt/pt-pt/termos.

Conforme exposto nos referidos Termos e Condições de Uso, o descarregamento de títulos de acesso restrito requer uma licença válida de autorização devendo o utilizador aceder ao(s) documento(s) a partir de um endereço de IP da instituição detentora da supramencionada licença.

Ao utilizador é apenas permitido o descarregamento para uso pessoal, pelo que o emprego do(s) título(s) descarregado(s) para outro fim, designadamente comercial, carece de autorização do respetivo autor ou editor da obra.

Na medida em que todas as obras da UC Digitalis se encontram protegidas pelo Código do Direito de Autor e Direitos Conexos e demais legislação aplicável, toda a cópia, parcial ou total, deste documento, nos casos em que é legalmente admitida, deverá conter ou fazer-se acompanhar por este aviso.

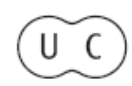




\section{Boletim de}

\section{Estudos Clássicos}

Associação Portuguesa de Estudos Clássicos Instituto de Estudos Clássicos

Coimbra

Junho de 2009 


\section{A Mestria do Poeta lírico: Notas sobre Horácio (7) ODE 2.3}

\section{Texto}

Aequam memento rebus in arduis seruare mentem, non secus in bonis ab insolenti temperatam laetitia, moriture Delli, seu maestus omni tempore uixeris seu te in remoto gramine per dies festos reclinatum bearis interiore nota Falerni.

Quo pinus ingens albaque populus umbram hospitalem consociare amant ramis? Quid obliquo laborat lympha fugax trepidare riuo?

Huc uina et unguenta et nimium breuis flores amoenae ferre iube rosae, dum res et aetas et sororum

fila trium patiuntur atra.

Cedes coemptis saltibus et domo uillaque, flauos quam Tiberis lauit, cedes et exstructis in altum diuitiis potietur heres.

Diuesne prisco natus ab Inacho nil interest an pauper et infima de gente sub diuo moreris: uictima nil miserantis Orci; 
Omnes eodem cogimur, omnium

uersatur urna serius ocius

sors exitura et nos in aeternum

exilium impositura cymbae.

\section{Tema}

Nos trilhos sinuosos da vida, de rumo incerto, mas inequívoco desfecho, uma só é a lição: a busca constante do meio termo, o culto da justa medida, a fidelidade à moderação.

Esta é a filosofia de vida que Horácio se não cansa de repetir nos seus versos, ode após ode, com ensinamentos colhidos da natureza, do tempo, da mitologia, da história. Qualquer que seja a condição humana de cada indivíduo, qualquer que seja a vida que em sorte lhe coube, um só é o destino que a todos aguarda: a morte, esse fim que a todos espera e que ele, o poeta, contempla, sempre, com um olhar misto de serenidade e melancolia, mas nunca com amargura.

Assim é nesta ode, sem dúvida de sabor epicurista, que abre com um apelo veemente à moderação: ânimo sereno, corra o tempo de feição ou seja a maré revolta.

Para tanto, procure o homem desfrutar das coisas boas da vida; um excelente vinho, por exemplo, que é sempre um bom arrimo, tanto na tristeza, quanto no repouso e calmaria (e este é outro dos temas recorrentes na poesia horaciana).

É isso, afinal, que nos ensina a natureza: a sombra hospitaleira das árvores frondosas, quando pinheiro e choupo acasalam os seus ramos, para nos acolher; a água que saltita nas curvas de riachos e arroios.

De tudo isso deve, pois, desfrutar o homem, com a serenidade de quem colhe o tempo, no seu lento transcorrer: flores, perfumes, vinhos, eis o que pode ajudar a viver, sem pressas, a idade que vai passando... até que chegue a hora final.

A hora derradeira - esse é o alerta, esse o aviso, essa a presença que jamais pode andar arredada da lembrança. A hora em que tudo se iguala, a hora em que vãos se tornam os gestos de grandeza, a hora em que os projectos imponentes redundam em frustração: no momento da partida, é a sós que se fará a viagem - tudo quanto a ambição desenhou e concretizou, tudo isso se quedará, irremediavelmente, nas mãos de herdeiros. 
Aí, não há distinção: nem de nascimento, nem de fortuna, nem de percurso. Como repetidamente afirma o poeta, a morte a todos nivela por igual; agitada a urna, o nome vem à sorte, seja quem for o seu titular; e, nesse dia, o caminho é o mesmo para todos.

Não é de tristeza, porém, a lição que destes versos se desprende, é, antes, uma lição eivada de sabedoria, porventura melancólica: conhecedor do que o espera, deve o homem saber cultivar a justa medida - menor será o tombo, por certo, e mais apaziguador o resultado.

\section{Estrutura}

Divide-se o poema, claramente, em duas partes, cada uma com três estrofes (respectivamente 1-3 e 5-7), entre as quais uma outra (est. 4) desempenha um papel, digamos, de ponte: na primeira metade, há um apelo, insistente, à moderação; a segunda evoca o destino que a todos aguarda, a morte; a estrofe 4, bem no centro, faz a ligação entre ambas, de forma sábia: gozemos dos frutos da natureza e dos prazeres (serenos) da vida, enquanto as Três Irmãs lhe não põem termo. Dois versos a recuperar, em jeito de síntese, as estrofes anteriores, dois versos a iniciar, sem subtilezas, as estrofes finais.

Ou seja:

Estrofes 1 e 2: conselho genérico, no sentido da moderação (importa notar que moriture, do verso 4 , antecipa já, sabiamente, o tema final).

Estrofe 3: ainda dentro do primeiro grupo, remete para a natureza, tomada como uma espécie de cúmplice do homem nessa busca de serenidade.

Estrofe 4: é, como se disse, o ponto de viragem do poema. Os dois primeiros versos aludem aos prazeres simples da vida - as flores, o vinho, os perfumes; mas os dois últimos (15-16), introduzidos, em jeito de alerta, pela temporal dum, fazem soar o alarme - até que o dia fatal acabe por chegar.

Estrofes 5 e 6 respondem, de algum modo, às duas iniciais: onde, ali, se apelava à moderação, aqui fala-se de excesso de riqueza, de bens, de mansões (versos 17-20); onde aquelas evocavam prazeres simples da vida, aqui anuncia-se, inevitável, a morte (21-24).

Estrofe 7: prossegue o tema que vem das duas anteriores, mas responde, em simultâneo, à primeira (moriture, do verso 4) e à quarta (fila atra, do verso 16) - a morte a todos acaba por levar, cega, inflexível.

A morte, enfim, dá unidade, como se disse, ao conjunto do poema: encerra a primeira estrofe, encerra, também, a quarta e é um bordão insistente nas duas últimas (moreris, v. 23; uictima Orci, v. 24; aeternum exilium, vv. 27-28). 


\section{Notas}

Aequam... mentem - sublinhe-se o modo como o poeta separa o substantivo, essencial para a compreensão da frase, do adjectivo que o qualifica e que é a base da advertência, colocado, este, estrategicamente, na abertura do poema. $\mathrm{O}$ mesmo se diga de laetitia, sugestivamente a abrir o verso final da primeira estrofe.

Merecem realce, igualmente, as sucessivas projecções, tanto de verso para verso, quanto de estrofe para estrofe, a indiciar um pensamento que não é compatível com pausas estruturais.

Insolenti...laetitia opõe-se, naturalmente, a aequam mentem. Já temperatam é uma espécie de explicitação (ou extensão) de aequam.

Moriture (vd. supra).

Délio: veterano das guerras civis, aqui convertido de actor no processo histórico recente em observador da vida que dele decorre (Quinn).

Seu maestus uixeris (5): opõe-se a insolenti laetitia. O sentido é claro: fruir os prazeres da vida deve ser uma norma, tão válida para os que vivem em contentamento, como para aqueles que experimentam momentos de tristeza, na medida em que o fim é, para ambos, igual.

Omni tempore, entre maestus e dies festos, dá uma amplitude generalizada ao incitamento em que se traduzem as duas primeiras estrofes.

Interiore Falernus: Falerno era um vinho do ager Falernus, na Campânia, muito afamado; interiore, porque os vinhos mais especiosos eram arrecadados no lugar mais recatado da adega, longe da entrada, onde se guardavam os mais correntes.

Vv. 9-12: exprime-se como que uma cumplicidade entre a natureza, assim quase personificada, e o homem. Árvores diferentes parecem unir os ramos para proporcionar ao homem conforto e prazer (esse é o sentido de consociare, no v. 10, reforçado por amant). Idêntica personificação, com semelhante objectivo, é a que se verifica com a alusão à água, que laborat e é fugax.

Huc (13): o convite à festa, com todos os ingredientes que se seguem.

Breuis flores rosae (13-14): a evocação da fragilidade e transitoriedade das flores, de que a rosa é um exemplo sugestivo, remete, subtilmente, para a transitoriedade da vida, que será o tema das estrofes finais.

Dum (15) - vd. supra.

Sororum trium: as três Parcas, Láquesis, Cloto e Átropos.

Fila atra (16) - vd. supra. Atra (negros) - cor que simboliza a morte. 
Cedes... cedes (17 e 19): anáfora sugestiva, que insiste na ideia dominante do poema - por mais que consigas construir e amealhar, tudo acabará por se esgueirar por entre os dedos e ficará entregue às mãos de um qualquer herdeiro, porque nenhum bem é duradouro.

Domo villaque: tanto as mansões (domo) como as casas de campo (uilla), tudo está sujeito ao mesmo destino.

Diues... pauper e prisco ab Inacho... infima de gente (21-22): antíteses recorrentes em Horácio, com este objectivo - a morte não distingue entre ricos e pobres, entre figuras de alta estirpe ou gente de baixa condição.

Ab Inacho: rei mítico de Argos, a simbolizar a aristocracia.

Victima (24): o homem é, assim convertido em vítima, elemento de um ritual de sacrifício de que todos seremos parte.

Eodem: "o mesmo destino".

Vrna: liga-se, ao mesmo tempo, à ideia de morte e à metáfora de exílio que, aqui, lhe está associada. Da urna era extraído, à sorte, o nome do que era votado ao exílio. Metaforicamente, essa é a incerteza que espera cada um dos seres vivos, que nunca sabe quando será o seu o próximo nome, sobre quem recairá a sentença. Essa sentença, aqui, é a cumba (28), a barca em que Caronte transportava os seus passageiros para a outra margem do Estígio.

\section{Tradução}

Lembra-te de, em tempo agreste, manter sereno

o ânimo e, em tempo propício, não menos equilibrado e livre de

desmesurada alegria, ó Délio, tu, que vais morrer,

quer todo o tempo tenhas vivido na tristeza,

quer nos dias de festa, deitado, longe, na relva

busques a felicidade,

com um Falerno do mais fundo da cave.

Para quê o enorme pinheiro e o choupo esbranquiçado

gostam de emparceirar a sombra hospitaleira

com seus ramos? Porquê porfia, saltitante, a água fugidia, nas curvas do ribeiro? 
Para aí, vinhos e perfumes e as flores, por demais fugazes, da tranquila roseira, é o que hás-de mandar trazer, enquanto a tua condição e a idade e os fios negros das três irmãs to consentirem.

Deixarás os campos que amealhaste e a casa e a quinta banhada pela corrente de oiro do Tibre, deixarás, ainda, as riquezas que no alto edificaste; delas há-de um herdeiro tomar posse.

Quer sejas rico, nascido do antigo Ínaco, ou pobre, de gente de baixa condição, nada te ajuda a retardares-te debaixo do céu, vítima que és do Orco sem piedade;

todos estamos sujeitos ao mesmo, a sorte de todos é revolvida na urna, e há-de sair, mais tarde ou mais cedo, e colocar-nos no batel, a caminho do exílio eterno. 